\title{
The examination of embryonic and fetal material in diagnostic histopathology laboratories
}

\author{
COLIN L BERRY
}

From the Department of Morbid Anatomy, The London Hospital Medical College, London E1 1BB, UK

\section{Introduction}

In many histopathology laboratories the amount of time and attention spent on assessing products of conception is derisory, often comprising no more than the examination of a single block to establish that pregnancy has occurred. This contrasts with the examination of putatively non-malignant lesions of the breast from which several blocks may be taken, sometimes with $x$-ray assistance, and where, if certain epithelial changes are present, step sections are frequently cut. The probability of finding a lesion of prognostic importance in the breast is extremely low. The probability of recurrence of a defect of the central nervous system or cardiovascular system or of a skeletal abnormality in an embryo or fetus exceeds $5 \%$ in non-assortative matings; for abnormalities associated with single genes of large effect the probability will be much higher. Much clinically valuable information is thus not gathered, and genetic counselling or antenatal investigation may not be carried out where it is necessary. If we assume Received for publication 18 November 1979

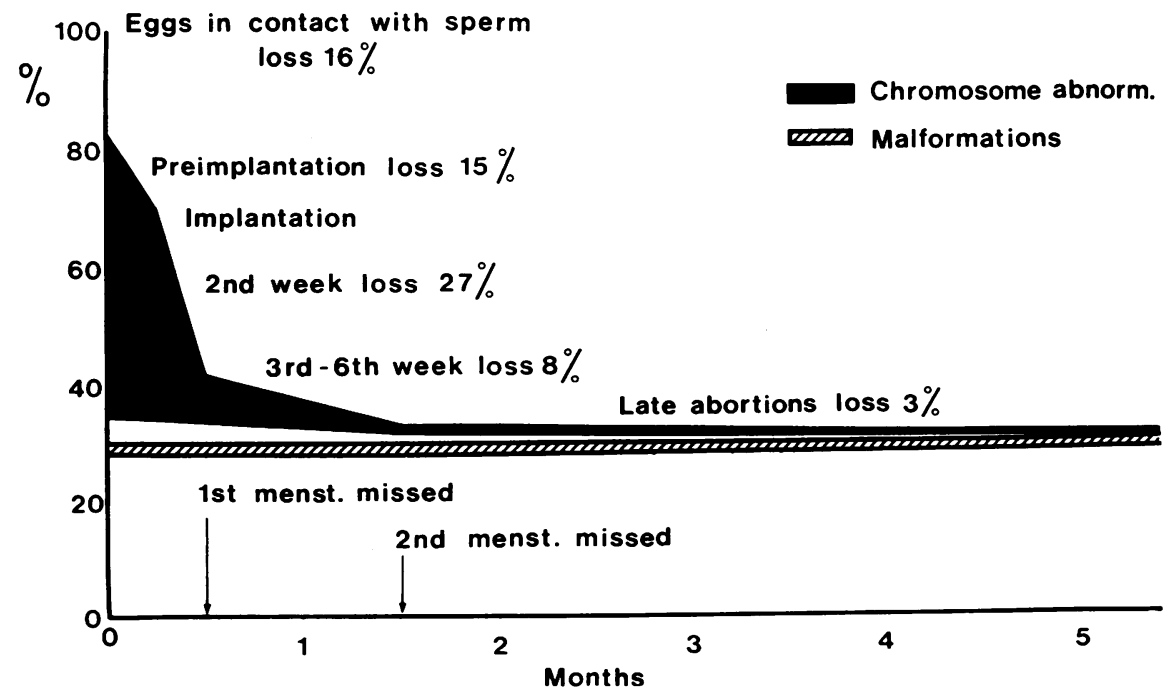

that more than $10 \%$ of aborted embryos will be abnormal (see below), it is salutary to examine pathological records and to see how frequently such anomalies are recorded.

What may usefully be done in a routine laboratory? Serial sections of early embryos are clearly not practicable, nor are they likely to be helpful since they would present problems in interpretation for pathologists without an embryological interest. I believe that such material should be studied in detail, and that it forms a valuable potential link between departments of anatomy and morbid anatomy, but it is clearly not a task for a consultant with a general service to provide. Towards the other end of the gestational period, larger fetuses-say, greater than $200 \mathrm{~mm}$ crown-rump length-can be examined in the same way as stillbirths or neonatal deaths, and the present review will not deal with this aspect of the problem. It is the intermediate stages, fetuses of $30-200 \mathrm{~mm}$ crown-rump length (say, 8 weeks' to 24 weeks' gestation), that can provide much valuable information from relatively little extra work.

Fig. 1 Causes of embryonic and fetal loss in early pregnancy. 


\section{Background data}

The majority of potential human fertilisations do not result in the production of a fetus. Figure 1, after Witschi, ${ }^{1}$ indicates where much of this reproductive loss occurs. From a number of studies it appears that about one-quarter of ova either fail to become fertilised or do not achieve the blastula stage. Failure of implantation occurs in a further $20 \%$ or so, and thus at 14 days after exposure of eggs to sperm almost half of the loss has occurred. Much of this reproductive failure is due to major chromosomal anomalies, including absence of any one autosome and some trisomic states.

In the next 28 days a further $10 \%$ or so of embryos are lost. Many of these are chromosomally abnormal, and some have major malformations. Subsequently there is little change in the number of conceptions going to term.

It can be seen that the 'normal' process of development is, in fact, exceptional. Errors are common and of varying type. The loss of an entire autosome obviously results in loss of too much genetic information to be tolerable. Massive failures of morphogenesis will also result in embryonic death; at its most obvious this may be expected when an amniote embryo fails to develop an effective circulation. Acardiac embryos develop only in the presence of a twin whose circulation perfuses the developing placenta effectively. Other reasons for spontaneous termination of pregnancy are less clear. Table 1

Table 1 Prevalence of some external malformations in 3000 embryos and fetuses compared with prevalence at birth

\begin{tabular}{lccc}
\hline Malformation & \multicolumn{2}{l}{ Prevalence per 1000} & \multirow{2}{*}{$\%$ Loss } \\
\cline { 2 - 3 } & Abortions & Births & \\
\cline { 2 - 3 } & & \\
\hline Neural tube & $13 \cdot 1$ & $1 \cdot 0$ & 92 \\
Cleft lip and palate & 24.4 & $2 \cdot 7$ & 87 \\
Polydactyly & 9.0 & 0.9 & 90 \\
Cyclopia and cebocephaly & 6.2 & $0 \cdot 1$ & \\
\hline
\end{tabular}

shows the prevalence of certain defects in abortions and at birth. Although death in early intrauterine life might be expected in massive neurospinal dysraphism, it is not clear why so many embryos or fetuses with polydactyly or cleft lip and palate are lost unless other unsuspected abnormalities are present. In the same way, the Turner phenotype is obviously compatible with extrauterine life, but losses of embryos of this genotype are severe and probably exceed $90 \%$.

Human malformations, defined as 'macroscopic abnormalities of structures attributable to faulty development and present at birth', ${ }^{2}$ occur at a frequency of around 25 per 1000 births in most large studies. These defects are clearly successful anomalies in terms of survival but represent a small percentage of abnormal conceptions. How small is uncertain, and better pathological studies are necessary to clarify this point.

\section{Examination of aborted embryos}

\section{HISTORY}

Historical details are as important in this field as they are with any other surgical specimen. Maternal age materially affects the probability of abnormality; menstrual dates are a valuable aid to dating. Drug ingestion (Table 2) or coincidental illness, for example, rubella, are clearly important in teratology and are discussed more extensively elsewhere. ${ }^{11}$ The previous reproductive history is also valuable, as is the state of health of other children or a family history of congenital or metabolic defects. If alpha-fetoprotein determinations have been made this should be stated; surprisingly, this information is not always given. Finally, the method used to induce abortion should also be stated.

MEASUREMENTS

The purpose of measurements is to assist in checking gestational ages.

Table 2 Agents known to be teratogenic in man* $\dagger$

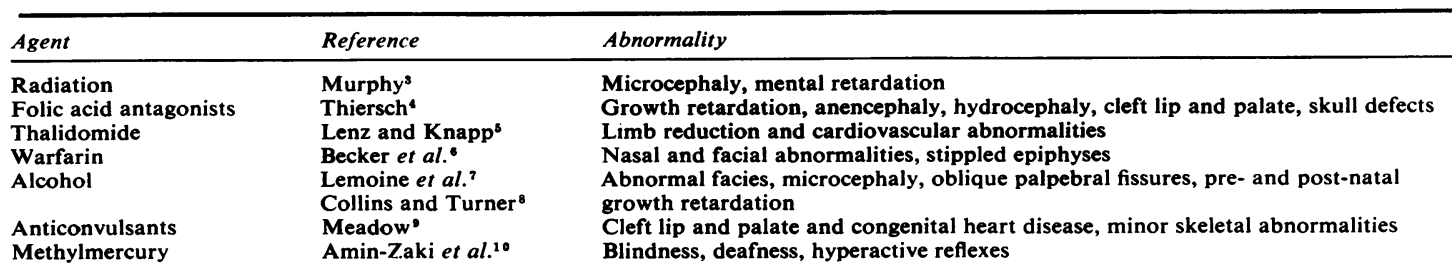

* Initial reports or those which contain data useful to the pathologist are cited here. Facies in the fetal alcohol syndrome are well illustrated in the paper of Collins and Turner.

†Testosterone and synthetic agents with progestational effects may cause virilisation of female fetuses. 
LINEAR DIMENSIONS

Measurements of the crown-rump or crown-heel length are not easy to make. Just as it has been realised that measurement of growth in children requires specialist techniques, so the work of Bagnall and his colleagues ${ }^{12}$ has illustrated the importance of techniques in fetal measurement. In practice, most pathologists are not able to use a carefully standardised procedure to measure fetuses, and the degree of flexure of the spine and limbs is difficult to control. Crown-heel length is also variably affected by fixation.

For these reasons, measurements of foot length are to be preferred (Fig. 2). Foot length correlated well with crown-rump length and is not significantly affected by fixation. In instances where the fetus is fragmented by abortion the feet generally remain intact. In certain circumstances where malformation affects the external form of the fetus, foot length is the only practicable measurement, and it is normal (in terms of length/gestational age) in anencephaly. ${ }^{15}$

\section{WEIGHT}

The weight of a fetus is prone to alter, depending on the method of abortion used, the type of fixation, or the delays in delivery to the laboratory. We have not found it to be useful unless fresh specimens can be obtained. However, there is valuable information to be obtained from fresh material. Golbus ${ }^{16}$ has illustrated the growth deficiency occurring with trisomic states, in particular, with trisomy 13 and 18 , which is evident in the second trimester. Trisomy 21 fetuses apparently grow normally, as Kučera and Doležalová17 18 have found. Nevertheless, the wide range of organ weights and other measurements found in the study of Golbus and Berry ${ }^{19}$, who examined 133 fresh fetuses between 90 and 170 postmenses, emphasises the lack of value of this

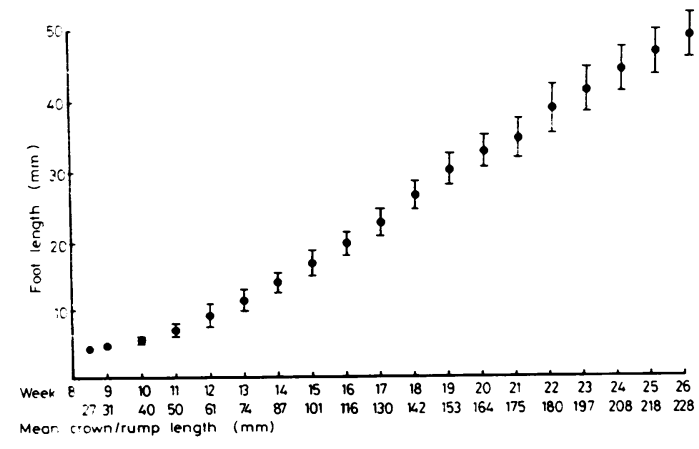

Fig. 2 Foot length and crown-rump length. Data from Streeter ${ }^{13}$ and Trolle. ${ }^{14}$ type of measurement for pathologists examining only a few cases a year.

\section{EXTERNAL EXAMINATION}

External examination may reveal many defects. Useful points to note in dating the fetus include whether the eyelids are separated (25-28 weeks) and, using a dissecting microscope, whether the fingerprints are present (10 weeks). I know of no case where the latter have been reported as abnormal in an early fetus, but there is no reason why abnormalities should not be recognised. It is also convenient to examine the palate at this time and to pass a probe into the nose to check the patency of the posterior nares.

Abnormal facies may be diagnostic (Fig. 3) or merely alert the pathologist to the possibility of internal abnormality (Fig. 4a, b).

It is then customary for us to $x$-ray the fetus using a Faxitron cabinet. This simple device permits rapid, within-department, $x$-ray pictures to be provided promptly (a Polaroid attachment is available) and will identify bony anomalies (Figs 5 and 6) which are better examined by further $x$-ray after removal of the viscera.

\section{INTERNAL EXAMINATION}

For all fetuses over $100 \mathrm{~mm}$ crown-rump length it is my view that a mininecrospy is the best procedure. However, the use of a modified Rokitansky technique is desirable, leaving the kidneys, ureters, and bladder in situ but removing all other viscera en bloc after examining the reflections of the mesentery. This block can then be examined using the dissecting microscope when necessary (Fig. 7).

For smaller fetuses, a modification of the Wilson ${ }^{20}$ free-hand sectioning method, used extensively on

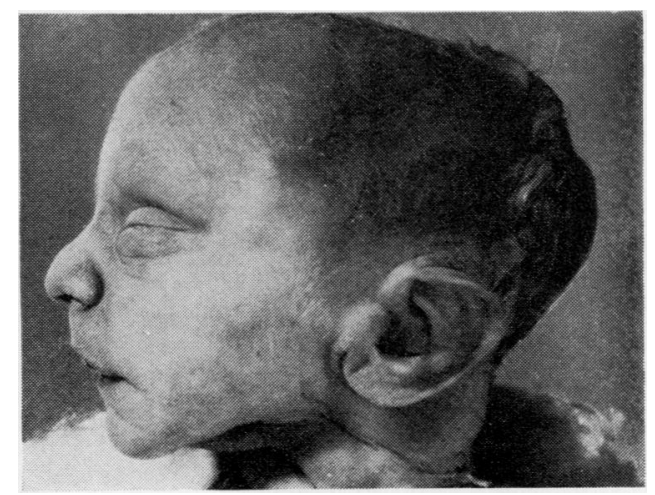

Fig. 3 Facies in a case of Potter's syndrome (near term). 


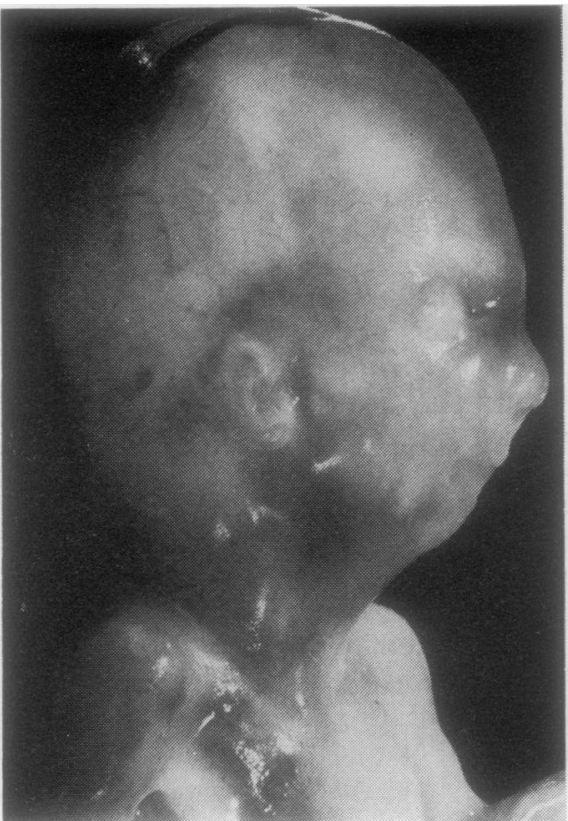

Fig. 4a

Fig. 4 weeks (courtesy of Dr M Becker).

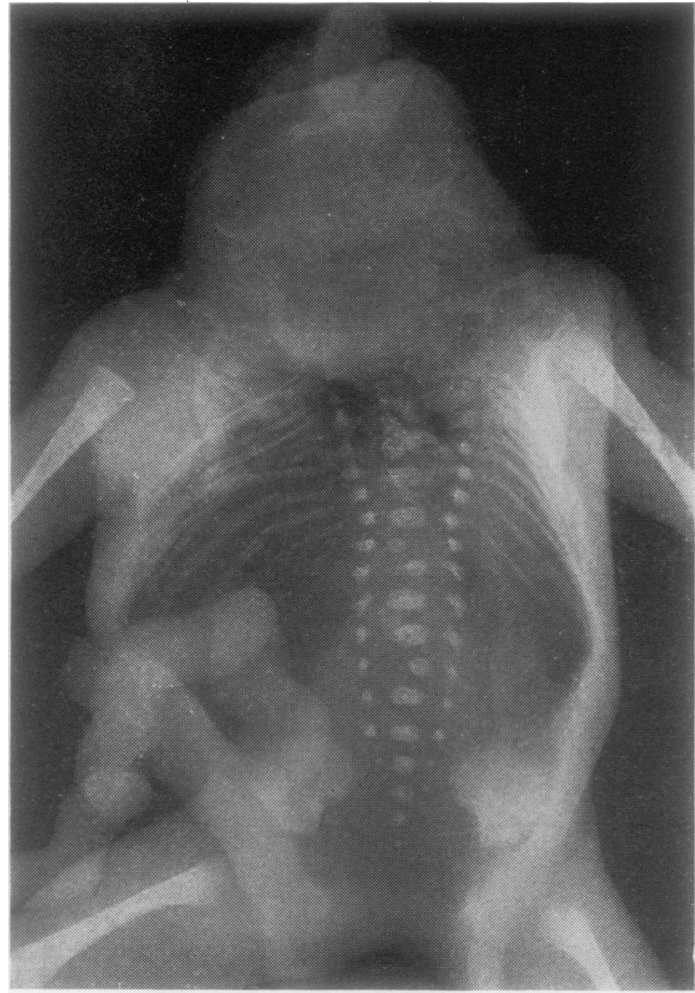

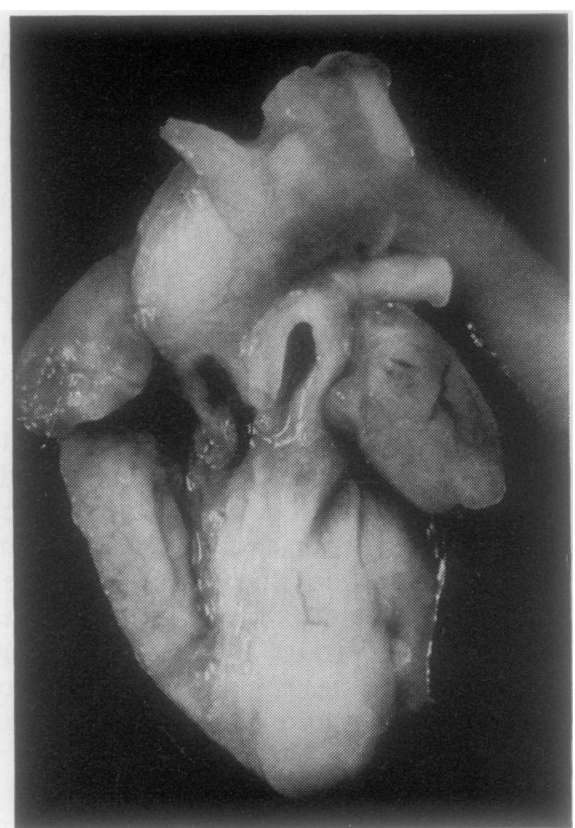

Fig. $4 \mathrm{~b}$

Fig. 5 Cerebral anomalies in anencephalic fetus.

Fig. 6 Narrowed chest with distention of abdomen in asphyxiation thoracic dystrophy (courtesy of $\mathrm{Dr} A$ Bain).

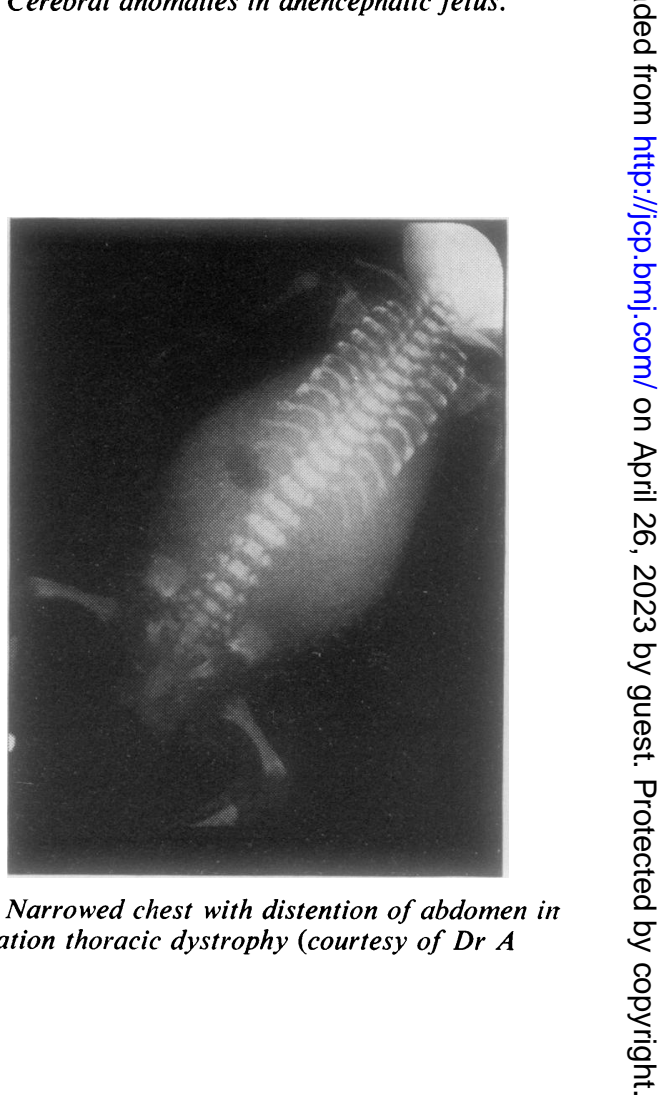


rodents in teratological studies, should be employed. Here the trunk of the embryo is cut into slices of approximately $1 \mathrm{~cm}$ thickness, and these are examined by dissecting microscopy. This technique is simple and thorough (Fig. 8a, b).

After removal of the viscera the skeleton is again $x$-rayed. This gives a good picture of the axial skeleton which, apart from specific abnormalities, provides useful information on dating. It is my view that the variability of the time of appearance of other primary centres of ossification makes them of dubious value in this type of exercise. However, vertebral body centres appear in a fixed sequence and with less variability (Fig. 9).

Where any tissue appears abnormal or any organ large or small, a block should be taken (Fig. 10).

\section{Abnormalities of specific systems}

When macroscopic anomalies are found the standard technique is often abandoned.

\section{Central nervous system anomalies}

In general, these should not be dissected as wet specimens. The cerebrospinal axis may be preserved as a unit and cut in large sections or transversely in a number of blocks (see Fig. 11). Recent reports ${ }^{21}$ have emphasised the value of histopathological examination of this type of specimen, which has rarely been performed. Insights into or alternative suggestions for pathogenesis may follow accurate documentation of the changes found. ${ }^{22}$ It must be remembered that examination of neurospinal malformations at term will illustrate the effects of injury or abnormality followed by up to eight months

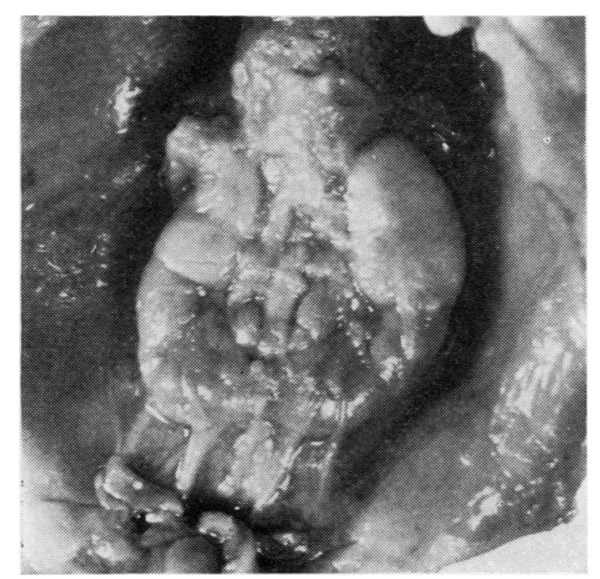

Fig. 7 Horse-shoe kidney in situ.
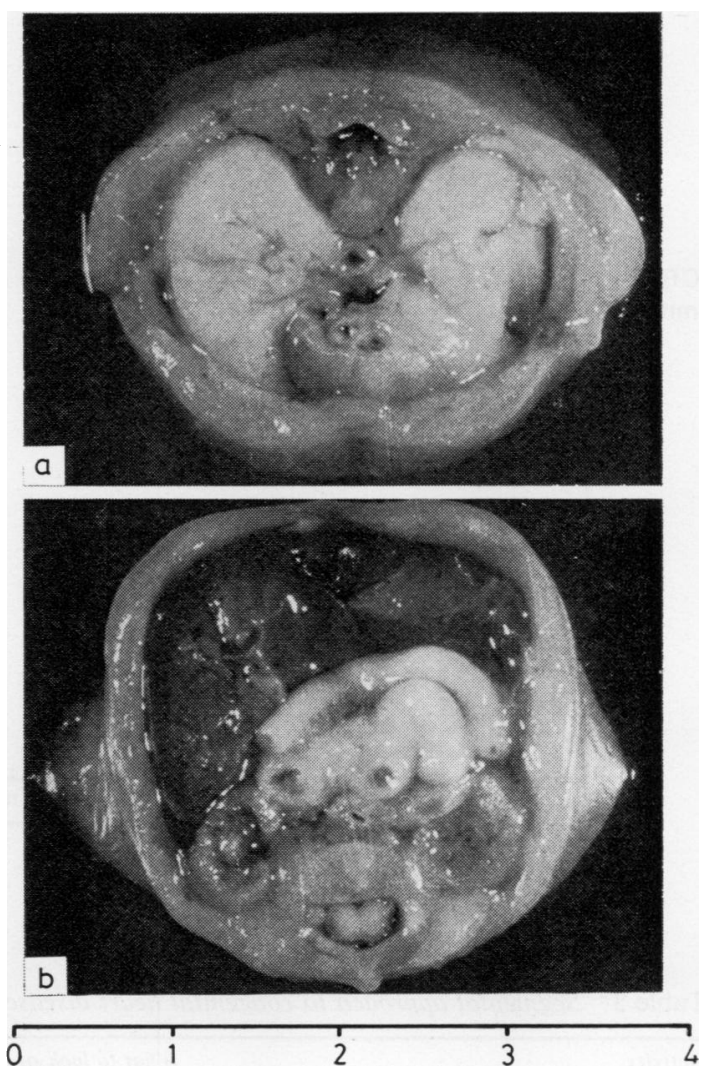

Fig. $8(\mathrm{a}, \mathrm{b})$ Slices through lower chest and upper abdomen. Examination of these slices from above and below using a dissecting microscope is an effective way of studying small embryos.

of attempted repair and further growth and will then yield little information about the pathogenesis.

\section{Cardiovascular system}

Even without an extensive knowledge of the vastly complex field of congenital heart disease a useful assessment of anomalies can be made if the system of Tynan and his colleagues ${ }^{23}$ is used. The key to their approach is a 'segmental' description summarised in Table 3. If the heart is classified in this way a description may be of considerable value to those expert in the field or for later checking, in a topic where photography is difficult and where the heart may not always be kept. The scheme shown is greatly simplified. It omits comments on ventricular details and the morphology of outflow tracts but still provides a basis for rational description. 


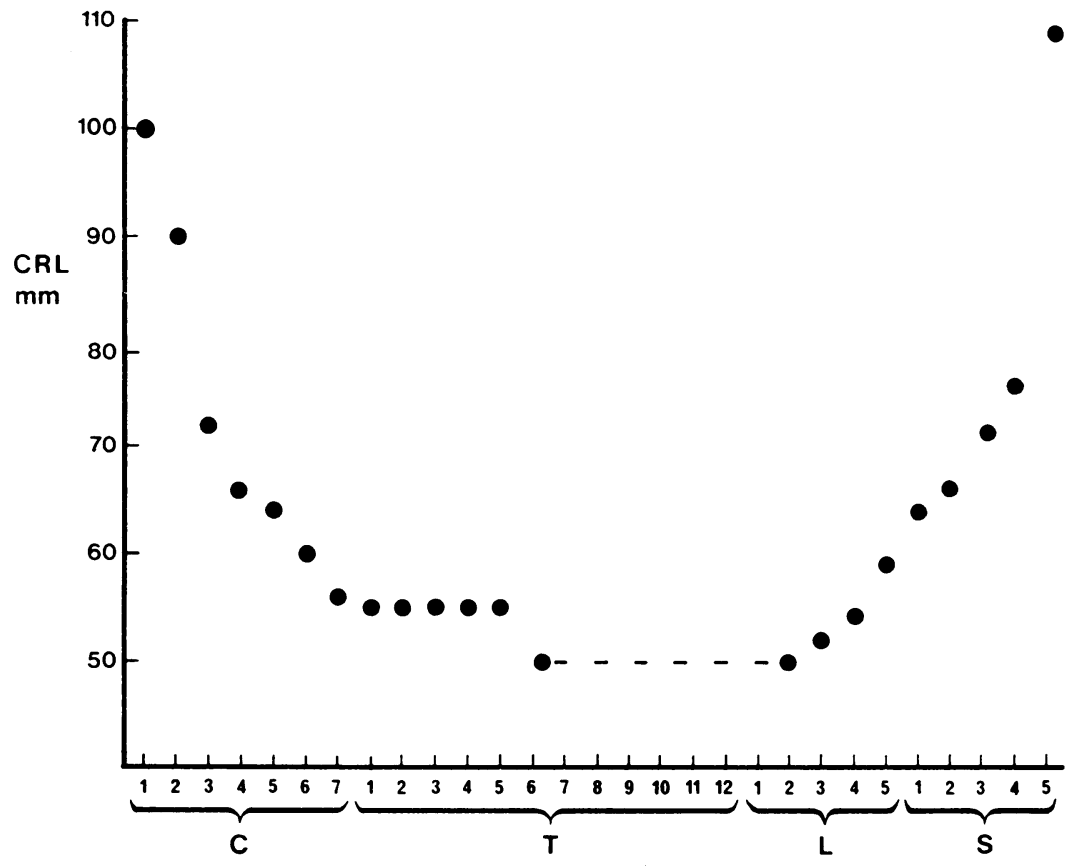

Fig. 9 Appearance of vertebral body ossification centres.

Table 3 Segmental approach to congenital heart disease

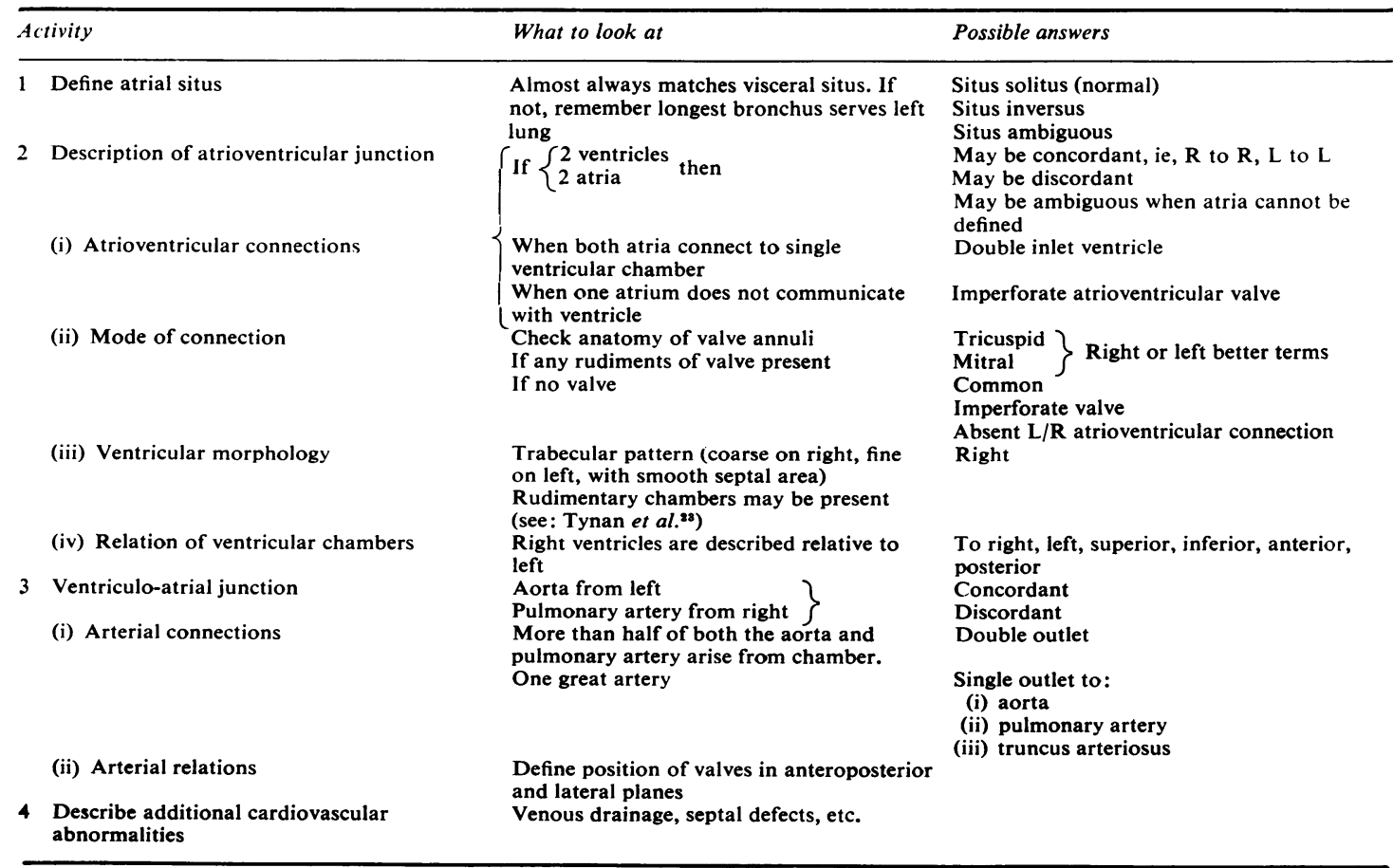

\footnotetext{
abnormalities
} 


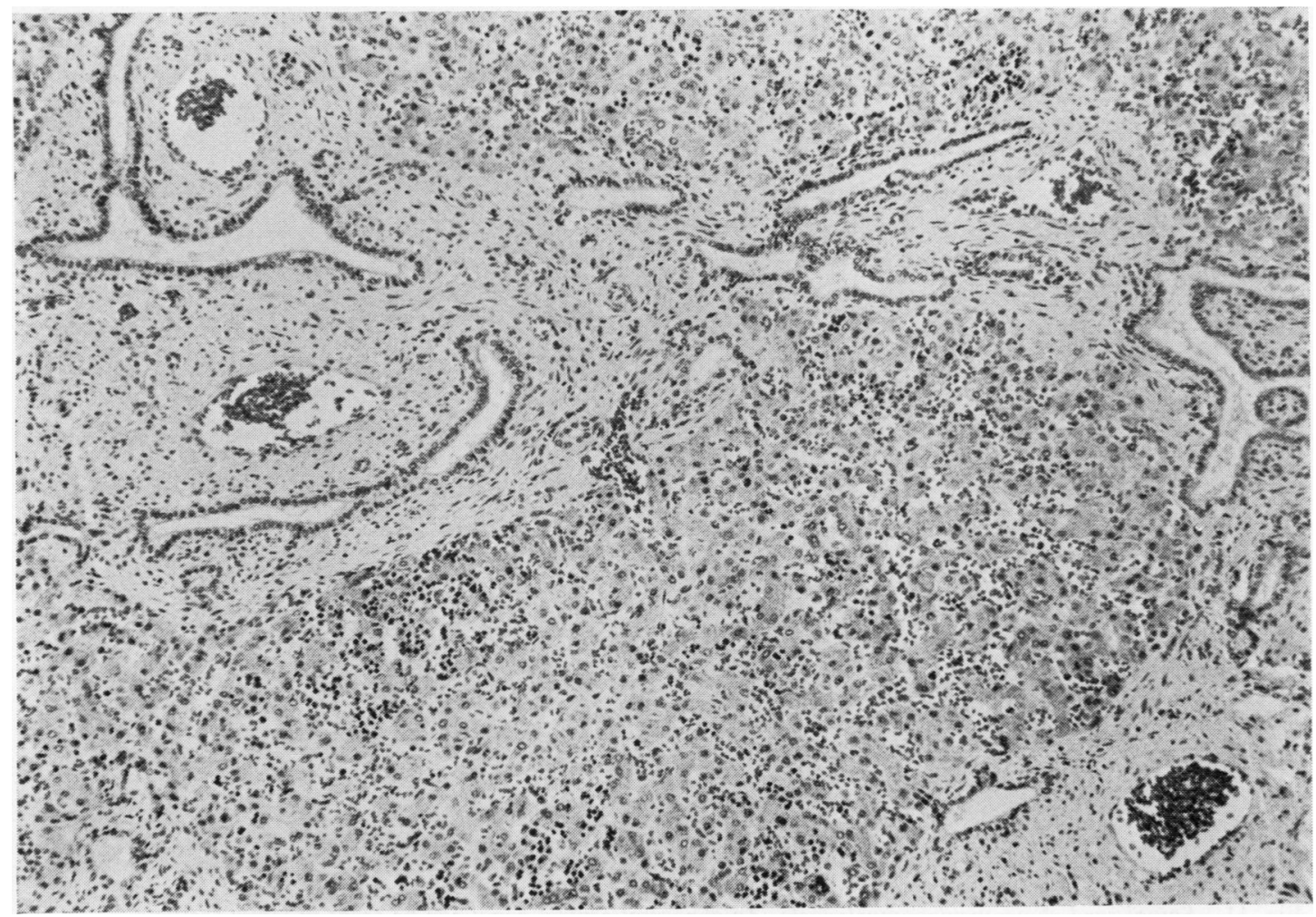

Fig. 10 Cystic change in bile ducts in enlarged liver from case of trisomy 18 (courtesy of Dr JW Keeling).

Haematoxylin and eosin $\times 200$.

\section{Musculoskeletal abnormalities}

These may be well defined by $x$-ray, but valuable data can be obtained by dissection. For example, extra digits can be defined by checking muscle insertions to see whether a 'thumb' is really a 'finger'. Abnormalities of this kind are ill defined but may also occur in association with limb teratogens. ${ }^{24}$

\section{Urogenital system}

After removal of the other viscera, the kidneys and ureters should be freed from the posterior abdominal wall. The pubes are then split and the pelvic viscera removed. Dissection, or fine probing, will then reveal where aberrant ureters drain or whether fistulae exist. Fine polythene catheters, heat-sealed at their ends, make good probes.

\section{Morphological disturbances in chromosomal anomalies: Placenta}

Even without an intact fetus some changes can be recognised. Triploidy is associated with changes in the chorionic sac, varying from mild changes in the villi to severe hydatidiform change. Although most triploid embryos are lost spontaneously, collected or therapeutically aborted material may show the changes described above and the presence of large, atypical cells in the villous stroma which may be of value diagnostically (see Ornoy et al. ${ }^{25}$ ). Interestingly, triploid cell lines are always associated with an embryo or fetus where cystic disease of the villi has been found, and triploidy is not associated with hyperplastic changes in the trophoblast. ${ }^{26}$

In a study of spontaneous human abortuses with normal and abnormal karyotypes, Honoré et al. ${ }^{27}$ were able to correlate placental morphology and the karyotype of the conceptus. Heteroploid abortuses could be differentiated from the diploid. Diploid placentae showed structural uniformity despite zonal differences, evidence of growth, and a coordinated development of trophoblastic epithelium and stroma. Secondary degenerative changes were seen superimposed on this pattern, and their severity depended on the length of time after intrauterine death that the conceptus had been retained. Heteroploid placentae showed disturbed morphology and failure of growth. Cystic villi were common, but 


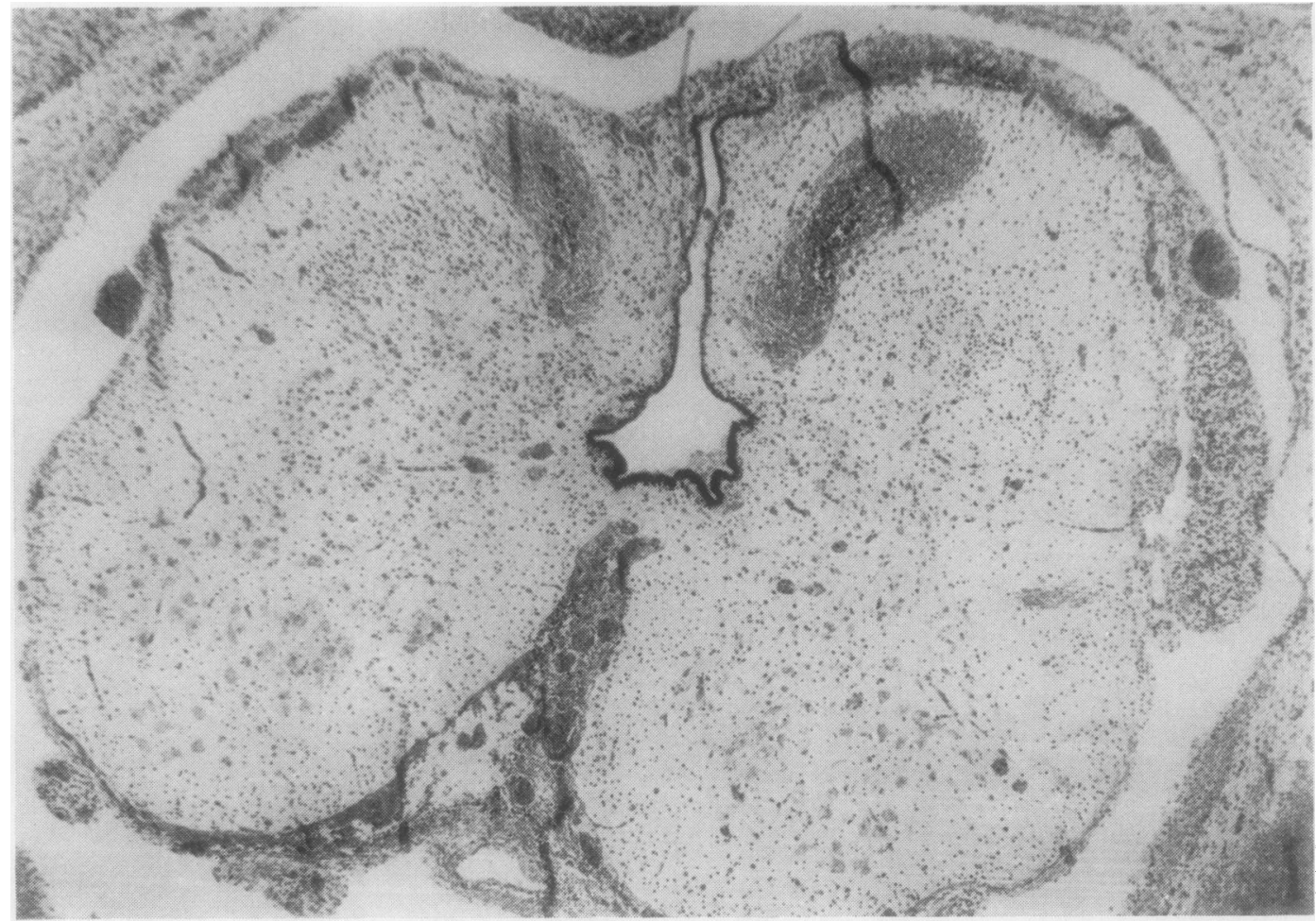

Fig. 11 Spinal cord above meningomyelocoele. An abnormal central canal can be seen; in lower sections this opens dorsally. Trichrome $\times 40$.

extensive cyst formation excluded monosomy $\mathrm{X}$ and tetraploidy; it was common in triploidy and trisomy. The characteristics described by these authors for various abnormalities are shown in Table 4.

\section{Metabolic abnormalities}

Prenatal diagnoses are usually made in selected groups. These include women over 35 years who are screened for chromosomal abnormalities and women who have previously given birth to an infant affected by a malformation, for example, neurospinal dysraphism. Metabolic disorders are usually sought only after an affected child has been diagnosed, which emphasises the value of examining abortion material. It is clearly absurd to suggest, however, that all abortions are examined for possible metabolic diseases, so the role of the pathologist is to look out for abnormalities that might be associated with metabolic disease. Foam cells in the placenta or central nervous system suggest lipidosis; some of the skeletal anomalies of the mucopolysaccharidoses are recognisable in fetal material, as are some features
Table 4 Changes in the placenta in heteroploid states

\begin{tabular}{ll}
\hline Anomaly & Placental change \\
\hline Trisomy & $\begin{array}{l}\text { Medium size, cystic villi with smooth outline. } \\
\text { Few trophoblastic buds. Intravillous } \\
\text { cystotrophoblastic cells. Hypoplastic trophoblast } \\
\text { on hypovascular villi } \\
\text { Diffusely macrocystic (submolar) pattern or, } \\
\text { more commonly, some large cysts and some } \\
\text { avascular villi. Stromal cells randomly arranged } \\
\text { in villi }\end{array}$ \\
Decidual and intraplacental haemorrhage \\
common. Hydropic villi mixed with hypovascular \\
compact villi. Many large immature stromal \\
cells, some hyperchromatic.
\end{tabular}

of the glycogenoses. Although 17 lipidoses, 11 mucopolysaccharidoses, 22 aminoacidurias or related disorders, 11 defects of carbohydrate metabolism, and 26 miscellaneous disorders have been diagnosed antenatally; a further $7,7,17,8$, and 15 disorders are potentially diagnosable in each category, respectively (see Milunsky ${ }^{28}$ ).

Alerting a clinical colleague to the possibility of 
the presence of such a disorder is of major importance in preventive terms.

\section{Conclusions}

It is only by the examination of fetal material that we can assess the true frequency and perhaps study the pathogenesis of human congenital defects. Observations on this material may also be valuable in other ways. Busulphan therapy is usually well tolerated in pregnant patients with chronic myeloid leukaemia; 12 patients have delivered normal infants on treatment. The report of myeloschisis in a six-week embryo of a similarly treated woman ${ }^{29}$ is thus put in perspective, and the high maternal age noted in this clear report assumes significance. In this way the additive environmental effects which are superimposed upon genetic predisposition to malformation may be identified in susceptible groups. The older woman is more likely to produce abnormal embryos and may thus be more susceptible to weak teratogens. Large-scale reporting of embryonic and fetal data from man will be more valuable than most animal studies.

\section{References}

1 Witschi E. Teratogenic effects from overripeness of the egg. In: Fraser FC, McKusick VA, eds. Congenital Malformations: Proceedings of the Third International Conference. Amsterdam, New York: Excerpta Medica, 1970:157-69.

2 McKeown T, Record RC. Malformations in a population observed for five years after birth. In: Wolstenholme GEW, O'Connor CM, eds. Ciba Foundation Symposium on Congenital Malformations, 1960: p. 2. London: Churchill.

${ }^{3}$ Murphy DP. The outcome of 625 pregnancies in women subjected to pelvic radium or roentgen irradiation. Am J Obstet Gynecol 1929;18:179-87.

4 Thiersch JB. Therapeutic abortions with a folic acid antagonist, 4-aminopteroylglutanic acid (4-amino PGA) administered by the oral route. Am J Obstet Gynecol 1952;63:1298-304.

${ }^{5}$ Lenz W, Knapp K. Foetal malformations due to thalidomide. Ger Med Mthly 1962;7:253-8.

${ }^{6}$ Becker MH, Genieser NB, Finegold M, Miranda D, Spackman T. Chondrodysplasia punctata: is maternal warfarin therapy a factor? Am J Dis Child 1975;129:356-9.

${ }^{7}$ Lemoine P, Harousseau H, Borteyro JP. Les enfants de parents alcooliques: anomalies observées. Quest Med 1968;25:477.

${ }^{8}$ Collins E, Turner G. Six children affected by maternal alcoholism. Med J Aust 1978;2:606-8.

${ }^{9}$ Meadow SR. Anticonvulsant drugs and congenital abnormalities. Lancet 1968;2:1296. (Letter)

10 Amin-Zaki L, Elhassani S, Majeed MA, Clarkson TW, Doherty RA, Greenwood M. Intra-uterine methyl- mercury poisoning in Iraq. Pediatrics 1974;54: $587-95$.

11 Berry CL. Congenital malformations In: Berry CL, ed. Paediatric Pathology. Berlin, Heidelberg, New York: Springer-Verlag, 1980.

12 Bagnall KM, Jones PRM, Harris PF. Estimating the age of the human foetus from crown-rump measurements. Ann Hum Biol 1975;2:387-90.

${ }^{13}$ Streeter GL. Weight, sitting height, head size, foot length, and menstrual age of the human embryo. Contrib Embryol Carnegie Inst 1920;11:143-70.

${ }^{14}$ Trolle D. Age of foetus determined from its measures. Acta Obstet Gynec Scand 1948;27:327-37.

${ }^{15}$ Nañagus JC. A comparison of the growth of the body dimensions of anencephalic human fetuses with normal fetal growth as determined by graphic analysis and empirical formulae. Am J Anat 1925; 35:455-94.

${ }^{16}$ Golbus MS. Development in the first half of gestation of genetically abnormal human fetuses. Teratology 1978;18:333-5.

${ }^{17}$ Kučera J, Doležalová V. Prenatal development of malformed fetuses at 28-42 weeks of gestational age (anencephalus, hydrocephalus, Down's syndrome, cleft lip and palate, and hypospadias). I Weight gains. Biol Neonate 1972;20:253-61.

${ }^{18}$ Kučera J, Doležalová V. Prenatal development of malformed fetuses at 28-42 weeks of gestational age (anencephalus, hydrocephalus, Down's syndrome, cleft lip and palate, and hypospadias). II Length gains. Biol Neonate 1973;22:319-24.

19 Golbus MS, Berry LC Jr. Human fetal development between 90 and 170 days postmenses. Teratology 1977;15:103-8.

${ }^{20}$ Wilson JG. Methods for administering agents and detecting malformations in experimental animals. In: Wilson JG, Warkany J, eds. TeratologyPrinciples and Techniques. Chicago: University of Chicago Press, 1965.

${ }^{21}$ Ganchrow D, Ornoy A. Possible evidence for secondary degeneration of central nervous system in the pathogenesis of anencephaly and brain dysraphia. A study in young human fetuses. Virchows Archiv $A$ 1979;384:285-94.

${ }^{22}$ Bell JE. Fused suprarenal glands in association with central nervous system defects in the first half of foetal life. J Path 1979;127:191-4.

${ }^{23}$ Tynan MJ, Becker AE, Macartney FJ, Jiménez MQ, Shinebourne EA, Anderson RH. Nomenclature and classification of congenital heart disease. Brit Heart $J$ 1979;41:544-53.

${ }^{24}$ Theisen CT, Bodin JD, Svoboda JA, Pettinelli MW. Unusual muscle abnormalities associated with thalidomide treatment in a rhesus monkey: a case report. Teratology 1979;19:313-9.

${ }^{25}$ Ornoy A, Kohn G, Zur ZB, Weinstein D, Cohen MM. Triploidy in human abortions. Teratology 1978; 18:315-20.

${ }^{26}$ Poland BJ, Baillie DL. Cell ploidy in molar placental disease. Teratology 1978;18:253-6.

${ }^{27}$ Honoré LH, Dill FJ, Poland BJ. Placental morphology in spontaneous human abortuses with normal and 
abnormal karyotypes. Teratology 1976;14:151-66.

${ }^{28}$ Milunsky A. Prenatal diagnosis of genetic disorders. $N$ Engl J Med 1976;295:377-80.

${ }^{29}$ Abramovici A, Shaklai M, Pinkhas J. Myeloschisis in a six weeks embryo of a leukemic woman treated by Busulfan. Teratology 1978;18:241-6.

Suggested reading

Berry CL. Congenital malformations. In: Berry CL, ed.
Paediatric Pathology. London, Heidelberg, New York: Springer-Verlag, 1980.

Warkany J. Congenital Malformations: Notes and Comments. Chicago: Year Book Medical Publishers, 1971.

Requests for reprints to: Professor CL Berry, Department of Morbid Anatomy, The London Hospital, London E1 1BB, UK.

\section{The March 1980 Issue}

\section{THE MARCH 1980 ISSUE CONTAINS THE FOLLOWING PAPERS}

The rôle of Chlamydia trachomatis in genital-tract and associated diseases D TAYLOR-ROBINSON AND BJ THOMAS

An evaluation of commercial radioisotope methods for the determination of folate and vitamin $\mathbf{B}_{12}$ DW DAWSON, IW DELAMORE, DI FISH, TA FLAHERTY, AH GOWENLOCK, LINDA P HUNT, K HYDE, JE MACIVER, JANET A THORNTON, AND HM WATERS

Interlaboratory comparison of serum vitamin $\mathbf{B}_{12}$ assay DL MOLLIN, AV HOFFBRAND, PG WARD, AND SM LEWIS

Collaborative study to recalibrate the International Reference Preparation of Anti-D Immunoglobulin HH GUNSON, PJ BOWELL, AND TBL KIRKWOOD

Measurement in jejunal biopsies by computer-aided microscopy GERARD SLAVIN, CHRISTOPHER SOWTER, KENNETH ROBERTSON, SUSAN MCDERMOTT, AND KEITH PATON

Microscopic amyloid deposits in the heart valves: a common local complication of chronic damage and scarring Y GOFFIN

Acute phase proteins, $\mathrm{C} 9$, factor $\mathrm{B}$, and lysozyme in recurrent oral ulceration and Behçet's syndrome THOMAS LEHNER AND MATTEO ADINOLFI
Sinusitis: an improved regime of investigation for the clinical laboratory RC BRIDGER

Prevalence and intraoral distribution of Candida albicans in Sjögren's syndrome L TAPPER-JONES, M ALDRED, AND DM WALKER

Antiseptic and antibiotic resistance in Gramnegative bacteria causing urinary tract infection DJ STICKLER AND B THOMAS

Sensitivity to carbenicillin and ticarcillin, and the $\beta$-lactamases of Pseudomonas aeruginosa in the UK in 1978-79 JULIE D KING, T FARMER, C READING, AND R SUTHERLAND

Evaluation of rapid methods of identifying group B streptococci SHEENA A WAITKINS

An outbreak of rotavirus infection in a long-stay ward of a geriatric hospital WD CUBITT AND H HOLZEL

\section{Technical methods}

Use of polylysine-coated slides in preparation of cell samples for diagnostic cytology OAN HUSAIN, JA MILLETT, AND JM GRAINGER

Reorienting gradient centrifugation in the determination of rubella specific IgM RH CAVE

Letters to the Editor

Book reviews

Copies are still available and may be obtained from the PUBLISHING MANAGER, BRITISH MEDICAL ASSOCIATION, TAVISTOCK SQUARE, LONDON WC1H 9JR, price $£ 3 \cdot 00$, including postage 